\title{
Correction to: Amitifadine, a triple reuptake inhibitor, reduces self-administration of the opiate remifentanil in rats
}

\author{
Edward D. Levin ${ }^{1} \cdot$ Corinne Wells $^{1} \cdot$ Andrew Hawkey $^{1} \cdot$ Zade Holloway $^{1} \cdot$ Graham Blair $^{1} \cdot$ Alexander Vierling $^{1}$. \\ Ashley Ko ${ }^{1}$. Caroline Pace ${ }^{1}$ • John Modarres ${ }^{1}$. Anthony McKinney ${ }^{2} \cdot$ Amir H. Rezvani $^{1}$ • Jed E. Rose ${ }^{1}$
}

Published online: 8 February 2021

(C) Springer-Verlag GmbH Germany, part of Springer Nature 2021

\section{Correction to: Psychopharmacology} https://doi.org/10.1007/s00213-020-05489-w

Our article published in Psychopharmacology had a typographical error in the units of remifentanil infusion for selfadministration.

The correct infusion dose of remifentanil is $0.3 \mu \mathrm{g} / \mathrm{kg} / \mathrm{infusion}$ not $0.3 \mathrm{mg} / \mathrm{kg} /$ infusion.

Publisher's note Springer Nature remains neutral with regard to jurisdictional claims in published maps and institutional affiliations.

The online version of the original article can be found at https://doi.org/ 10.1007/s00213-020-05489-w

Edward D. Levin

edlevin@duke.edu

1 Department of Psychiatry and Behavioral Sciences, Duke University School of Medicine, Durham, NC 27710, USA

2 Ethismos Research, Inc, Cambridge, MA, USA 